\title{
O segredo como fato, o fato como segredo
}

\author{
Suely KofeS
}

Social Anthropology deals at present in crude concepts, tribe, clan, age-set, orc, representing social masses and a supposed relation between these masses. The science will make little progress on this low level of abstraction, if it be considered abstraction at all, and it is necessary for further advance to use the concepts to denote relations, defined in terms of social situations, and relations between these relations. (Evans-Pritchard, 1940, p. 266)

Social anthropology became the science of descent groups, and descent groups and their constitution came to be crucial issues in accounting for the core function of integrating society and keeping it together. (Roy Wagner, 1974, p. 97)

What intrigues me is the consistent parallel, the repeated echo, between intellectual propagation and procreative acts, between knowledge and kinship. (Marilyn Strathern, 1995, p.8)

A primeira epígrafe foi extraída do último parágrafo do livro Os Nuer (The Nuer), de Evans-Pritchard. $\mathrm{Na}$ frase seguinte ao trecho citado ele diz da dificuldade de explorar novas possibilidades na política da disciplina, na qual táo pouco estava sendo feito. Sentimo-nos como um explorador no deserto, confessa [We feel like an explorer in the desert whose supplies have run short]. Digamos que esta confissão, somada às outras monografias que ele escreveu, nos permita problematizar o alinhamento de Evans-Pritchard aos teóricos da teoria da descendência que está sob crítica no artigo de Roy Wagner - este importante artigo, "Are There Social Groups in the New Guinea Highlands?", que finalmente Cadernos de Campo nos oferece ao publicar a tradução de Iracema Dulley. Temos agora o artigo "Existem grupos sociais nas terras altas da Nova Guiné?".

Até muito recentemente - na minha experiência, até duas semanas atrás -, ao perguntar a alunos de graduação qual a etnografia que leram em seus cursos de antropologia, ouvimos a resposta usual de que foi Os Nuer.

Talvez isto se deva - embora sem explicar inteiramente - à sua tradução precoce em relação às publicações de etnografias pelas editoras brasileiras. O livro de Evans-Pritchard foi publicado em 1978, antes inclusive de Os Argonautas do Pacifico Ocidental (etnografia publicada em 1984). O contraponto entre essas duas monografias clássicas é bem conhecido e vem sendo alimentado anos seguidos, embora os programas de antropologia para alunos de graduação já contem com outras traduçôes de experiências etnográficas e conceituais como, inclusive, O gênero da dádiva (2006).

Neste quadro, faltava o artigo de Roy Wagner, mesmo que a pergunta provocadora de seu título já tenha sido estendida e estimulado intensas controvérsias, particularmente quando respondida por um "nem lá, na Nova Guiné, nem aqui", a se levar em conta os supostos do "reassembling the social".

Sem deixar de saudar a edição em português de $A$ invenção da cultura, anseio por um entusiasmo editorial para a publicação também das etnografias de Roy Wagner. 
232 Suely Kofes

\section{Apresentando brevemente um autor já bem conhecido}

Roy Wagner nasceu em Cleveland, Ohio, 1938, em uma família originária de Hamelin, Baixa Saxônia, e foi seu bisavô quem imigrou para os Estados Unidos em 1890. Wagner recebeu seu Ph.D. em antropologia pela Universidade de Chicago (em 1966, depois de iniciar um curso de astronomia em Harvard e licenciar-se em história medieval), onde estudou com David M. Schneider. Lecionou na Southern Illinois University, na Northwestern University, e está atualmente na Universidade de Virgínia.

Considerando a linguagem e os símbolos como ferramentas humanas, a obra de Wagner explora as implicaçóes disto para a antropologia como ciência, em seu objetivo de descrição da realidade. Como ao fazer significações também nos fazemos, Wagner afirma a importância do ato de diferenciar modos de simbolizaçáo, de estudar mundos conceituais específicos, sendo cada estilo de criatividade também um estilo de compreensão.

Não conheço pessoalmente o professor Roy Wagner, nem poderia lhes revelar algo de sua biografia que não seja o publicado. Seria interessante analisar a sua narrativa sobre si mesmo na entrevista concedida a Alan MacFarlane em 9 de junho de 2008, mas não o fiz. Considerando-me apenas uma leitora estudiosa, e ainda bem iniciante, de Lethal Speech (1978) e Symbols that Stand for Themselves (1986a), interessada em compreender sua teoria da obviação e da metáfora como geradora de significado, deixo para os leitores o endereço da entrevista a que me referi: www.alanmacfarlane.com/ancestors/wagner.htm. Assim, além de lerem seus livros, poderão também ouvi-lo contar histórias sobre si mesmo e sobre os livros que publicou, particularmente $A$ invenção da cultura ${ }^{l}$.

Wagner introduziu conceitos importantes para a antropologia. $\mathrm{O}$ artigo agora traduzido,
"Existem grupos sociais na terras altas da Nova Guiné?" ("Are There Social Groups in the New Guinea Highlands?”, de 1974), é uma crítica às teorias de parentesco da descendência e da aliança. Deslocando a consaguinidade de sua função constituidora de grupos delimitados jurídica e politicamente, Wagner argumenta que na Nova Guiné os grupos são explicitados através de atos criativos, na distribuição de presentes e na partilha de carne. $\mathrm{O}$ conceito de criatividade aparece como condiçáo da cultura, incorporando ao conceito de cultura a experiência de conhecimento: "O que o pesquisador de campo inventa, portanto, é seu próprio entendimento: as analogias que ele cria são extensóes das suas próprias noçóes e daquelas de sua cultura, transformadas por suas experiências da situação de campo" (Roy Wagner, 2010, p. 40).

A primeira parte do artigo sobre a existência ou não dos grupos sociais na Nova Guiné é um trajeto breve pela teoria antropológica em sua versão "britânica" e, brevíssimo, pela teoria de parentesco de Lévi-Strauss (a de 1949), que lhe permite constituir o alvo de sua crítica: a existência de grupos sedimentados, predefinidos, "criados" pela teoria da descendência; o caráter normativo do social, "criado" pela teoria da aliança; e o caráter sistêmico de ambas as teorias, a da descendência e a da aliança.

Este percurso de Wagner, entretanto, não tem o alcance que teve aquele que foi realizado por Lévi-Strauss em Le Totemisme Aujourd'hui (O totemismo hoje), embora possamos lhe atribuir um objetivo similar (possivelmente o seu efeito): o de elaborar um percurso pelas teorias anteriores tendo em vista uma crítica avassaladora aos seus fundamentos, para em seguida expor os seus próprios supostos teóricos. Mas, no caso do percurso de Wagner no presente artigo, há certa frouxidáo argumentativa e uma superficialidade na exposição das perspectivas visitadas, além de pouca ou nenhuma sutileza ao agrupar os autores sob a carapuça da teoria 
O SEGREDO COMO FATO, O FATO COMO SEGREDO $\mid 233$

da descendência. Em compensação, ele formula com nitidez o quadro ao qual vai se contrapor e desenha com eficácia o alvo de sua crítica.

A força deste texto está, portanto, em conciliar num artigo curto uma configuração etnográfica $\left(\right.$ daribi) ${ }^{2}$ e um pressuposto teórico instigante e polêmico, qualidades que surgem ocasionalmente na antropologia assegurando-lhe sua vitalidade. Este artigo pode ser considerado como um ângulo expressivo na trajetória de Wagner e na da antropologia.

\section{Sobre a tradução de "Are There Social Groups in the New Guinea Highlands?" e as minhas boas-vindas a ela}

Mesmo atribuindo a Durkheim a responsabilidade pelos fundamentos da antropologia social (conforme Wagner, tais fundamentos seriam as "forças e influências que mantêm os seres humanos juntos, sua "grupidade" em todos os aspectos - como um fenômeno a ser investigado cientificamente"), o alvo da crítica de Wagner é mais a sua ressonância na teoria do parentesco anglo-saxã, como uma teoria de integração social ("A suposição "político-jural" foi a contribuição de uma tendência britânica de pensamento muito secular e pragmática ao problema original de Durkheim").

$\mathrm{O}$ artigo de Wagner começa com uma reflexão crítica sobre a dicotomia entre sociedade (relaçóes sociais) e cultura (linguagem, conceitos e concepçóes) e a correspondente divisão da antropologia em antropologia social e cultural. A primeira, antropologia social, figura "como ciência dos grupos de descendência" (grupos vistos como tendo a função de integração da sociedade) - embora seja preciso assinalar que o uso do termo antropologia social na antropologia britânica antecede os sentidos desta dicotomia apontada por Wagner e que o conceito de sócio-mythique em Leenhardt (1947) ${ }^{3}$, instigando um conceito que funde morfologia e cosmologia, cosmomorforlogia, em solo durkeimiano, desafia o suposto dessa dicotomia (se o mérito é da Melanésia, esta é uma boa discussão, já em andamento).

O meu desconforto (bem positivo, aliás) com este artigo de Wagner é que ora ele parece nos remeter à inadequação da teoria - a teoria da descendencia e sua invenção do grupo integrado - aos Daribi; ora ela seria inadequada mesmo aos povos africanos aos quais foi aplicada; ora ele afirma sua correspondência (e, aparentemente, sua única adequação) "com os grupos conscientemente organizados, planejados e estruturados da sociedade ocidental".

O melhor mesmo é quando, neste artigo, Wagner desloca-se da discussão sobre as adequaçóes ou inadequaçóes da referida teoria que, formulando o conceito de grupo social, generaliza previamente sua realidade e concebe a sociedade como sua extensão - a esta ou aquela empiria e explicita a crítica ao seu fundamento: o de que ela corresponderia apenas ao "nosso entendimento do que as pessoas estavam fazendo, e não do que elas mesmas faziam".

Assim compreendido, o artigo de Wagner afirma o que será repetido em boa parte de seus escritos: "Elas sugerem que nós somos táo criadores quanto os povos que estudamos, e precisamos prestar atenção tanto à nossa criatividade quanto à criatividade deles. Dito de modo um pouco diferente, a suposiçáa da criatividade coloca o antropólogo em igualdade de condiçóes com seus sujeitos de pesquisa; também o nativo é um "antropólogo", com sua própria "hipótese de pesquisa" sobre seu modo de vida. E a despeito de como desejamos compor esse modo de vida, temos de avir-nos com a "teoria" do próprio nativo por uma questão de dever profissional e ético".

A tensão entre generalização e exceções etnográficas é uma constante na antropologia, 
que se não deixa de reconhecer a importância da perspectiva etnográfica, também lembra de vez em quando, e muitas vezes, a distinção que não deveria ser confundida entre nomotético e ideográfico, entre etnografia e antropologia.

Parece que em alguns momentos Wagner está dizendo algo sobre isto, mas não é isto o que repete Wagner. Trata-se do desafio da indissolubilidade do que algumas teorias convencionaram separar, as "relaçóes sociais e o que as pessoas pensam sobre elas". Deste ponto de vista, o que pareceria ser o ideográfico para a antropologia seria (ou deveria ser) a antropologia do etnografado.

$\mathrm{Na}$ primeira parte do artigo, a incursão rápida pela teoria antropológica, a crítica de Wagner não é apenas à teoria da descendência, conforme desenvolvida pela antropologia britânica. Embora reconhecendo que o grupo social aparece na antropologia sob novo aspecto - mais conceitual do que material - em Les Structures Élémentaires de la Parenté, a proibição do incesto, ao inaugurar o universo da regra, conforme Lévi-Strauss, instituiria a reciprocidade e a organização.

Ou seja, para Wagner, tanto a antropologia social britânica quanto o estruturalismo francês não prescindem da exigência do sistema, e, portanto, da ordem - como atribuição do parentesco e do entendimento do antropólogo.

Uma vez formulada a equivalência sistêmica entre os "grupos corporados" rígidos, empíricos e materiais dos antropólogos sociais e os constructos conceituais dos estruturalistas, Wagner estende a pergunta do título do artigo: "por que, afinal, precisamos explicar as estruturas sociais por meio dos grupos?"

A resposta parte da criação conceitual como fonte do "como se". O "como se" efetua a similaridades dos "nativos" através das noçôes de grupo e de coerência do antropólogo. A semelhança, assim, obliteraria o "modo 'nativo' de fazer a sociedade", quando o que importaria para Wagner é "a forma como as pessoas se criam socialmente". Uma antropologia assim concebida não se satisfaz em aplicar as noçôes sedimentadas de grupos, mas quer perguntar, no caso aos povos da Nova Guiné, como criam sua socialidade e se eles têm a "sociedade como problema”. Como disse Wagner, "os Daribi na minha aldeia deram-me uma espécie de apelido - Hanarubo - que significa 'ele pergunta continuamente ou habitualmente' [The Daribi people in my village had a sort of nickname for me, Hanarubo, meaning he continually or habitually asks'] (Wagner, 2000).

Explicitada a sua crítica, e os seus supostos, entra então em campo o pesquisador de campo, e a narrativa etnográfica de Wagner nos leva à socialidade daribi.

\section{Para is a name, not a group}

Imaginemos que haja um nexo entre o totemismo e o parentesco como ilusão ${ }^{4}$, respectivamente, em Claude Lévi-Strauss (1962) e David Schneider (1965; 1968; 1984). Se esta relação pode ser percebida, ela toma forma neste artigo de Wagner.

A entrada na narrativa etnográfica de Wagner nos faz conhecer os "termos gerais" (como "pessoas de casa") e os "termos específicos" (como Weriai, Kurube e Noru) que seriam parte dos meios (vastos e sempre em expansão, diz o autor) usados pelos Daribi para expressar distinçôes sociais. Mas, se os termos efetuam distinções, não fazem referência a grupos sedimentados e efetivamente distinguíveis.

"Os termos são nomes, não são as coisas nomeadas", diz Wagner.

Valem pela diferença que fazem, diz o autor, citando a já bem conhecida fórmula de Lévi-Strauss sobre o totemismo (Não são as semelhanças, mas as diferenças, que se assemelham). Para é um dos nomes pouco específicos que, 
O SEGREDO COMO FATO, O FATO COMO SEGREDO $\mid 235$

menos do que representar um grupo, aparece para operar fronteiras, criar contrastes e eliciar. Para exemplifica a eliciação como um modo criativo (estilo) daribi.

$\mathrm{Na}$ descriçáo da troca e dos contrastes de gênero, vemos a criação de significação cultural e relação social se fazendo juntas. $\mathrm{O}$ parentesco (como relatedness) se torna compreensível não pela relação entre grupos políticos socialmente diferenciados, mas pelos fluxos de relaçóes analógicas (as relaçôes e "tipos" de parente sendo essencialmente similares) como consequência da diferenciação dos parentes e dos conceitos que expõem a diferença. Os conteúdos implícitos, os atos de diferenciação explícitos parecem exigir a performance bem-sucedida, isto é, a capacidade de atualizar o contexto associativo implícito na "socialidade permanente". Isto querendo dizer que "as pessoas traçam fronteiras, impelem e eliciam, e as relaçóes tomam conta de si mesmas". Tal ação criativa, não sistemática, do Daribi não seria perdida depois da chegada dos brancos, como mostra o final do artigo, em um exercício bem conduzido na descrição das perspectivas agrupadoras, de atribuição de identidades, de deslocamentos flexíveis dos nomes em relaçáo aos referentes sociais, improvisando nomes e agrupamentos. A socialidade daribi, diz Wagner, assume uma aparência distinta a cada mudança de perspectiva do observado.

Afirmaçóes como estas já circulam com certa frequência em produçóes da antropologia no Brasil, em traduçóes como a de $O$ gênero $d a d a ́-$ diva. Difícil dizer qual, e em que momento, foi a pedra no lago que provocou esta onda, mas ela certamente poderia ser este artigo.

\section{Notas}

1. Eis um resumo de suas obras: An Anthropology of the Subject (2001); The Reprojective Basis of Human society (2000b); Asiwinarong: Ethos, Image, and Social Power among the Usen Barok of New Ireland (1986b);
Symbols that Stand for Themselves (1986a); The Invention of Culture (1981); Lethal Speech: Daribi Myth as Symbolic Obviation (1978); Habu: The Innovation of Meaning in Daribi Religion (1972).

2. O que pode ser bem completado pela leitura de Wagner, 1977.

3. Ver, como exemplo, a discussão das páginas 266-271 da segunda edição de Do Kamo, de Maurice Leenhardt (1971).

4. Ilusão, respectivamente, o totemismo, como fenômeno, e o parentesco, como organização social.

\section{Referências bibliográficas}

EVANS-PRITCHARD, E. E. The Nuer. Oxford: The Clarendon Press, 1968 [1940].

LEENHARDT. Maurice. Do Kamo. Paris: Gallimard, 2a edição, 1971 [1947].

LÉVI-STRAUSS. Claude. Le totemisme aujourd'hui. Paris: Presses Universitaires de France, 1962.

SCHNEIDER, David. Some Muddles in the Models: or, How the System Really Works. In: The Relevance of Models for Social Anthropology. A.S.A. Monograph No. 1. Londres: Tavistock Publications; Nova York: Frederick A. Praeger, 1965.

American Kinship: A Cultural Account. Englewood Cliffs: Prentice-Hall, 1968.

. A Critique of the Study of Kinship. Ann Arbor: University of Michigan Press, 1984.

STRATHERN, Marilyn. The Relation. In: Prickly Pear Pamphlet, 6. Cambridge: Prickly Pear Press, 1995.

- O gênero da dádiva. Campinas: Editora da Unicamp, 2006 [1988].

WAGNER, Roy. Habu: The Innovation of Meaning in Daribi Religion. Chicago: University of Chicago Press, 1972.

. Are There Social Groups in the New Guinea Highlands? In: LEAF, Murray. (Ed.) Frontiers of Anthropology. Nova York: D. Van Nostrand Company, 1974. pp. 95-122.

. Analogic Kinship: A Daribi Example. In: American Ethnologist, vol. 4, n. 4, 1977. . Lethal Speech. Daribi Myth as Symbolic Obviation. Ithaca: Cornell University Press, 1978. Symbols that Stand for Themselves. Chicago: University of Chicago Press, 1986a. Asiwinarong: Ethos, Image, and Social Power among the Usen Barok of New Ireland. Princeton: Princeton University Press, 1986b.

cadernos de campo, São Paulo, n. 19, p. 231-236, 2010 
$236 \mid$ Suely Kofes

Our Very Own Cargo Cult. In: Oceania, v. 70 (4), Sydney, 2000a.

. The Reprojective Basis of Human society. In: Soumen Antropologi, Journal of the Finish Anthropological Society, 2000b.
An Anthropology of the Subject. Berkeley: University of California Press, 2001.

- A invenção da cultura. São Paulo: Cosac \& Naify, 2010 [1981].

autora Suely Kofes

Professora do Departamento de Antropologia / Unicamp

Livre-docente em Antropologia Social / Unicamp

Recebido em 22/10/2010

Aceito para publicação em 20/10/2010

cadernos de campo, São Paulo, n. 19, p. 231-236, 2010 